\title{
Articulação de Redes Sociais por Empreendedores na Formação do Capital Social: um estudo de caso de uma empresa do setor de turismo do interior do Paraná
}

\author{
Social Networks Connections by Entrepreneurs in the Formation of Social Capital: a case \\ study of a tourism enterprise in Paraná state countryside
}

Norma Pimenta Cirilo Ducci ${ }^{1}$

Rivanda Meira Teixeira ${ }^{2}$

\begin{abstract}
Resumo
$\mathrm{Na}$ criação de novos negócios os empreendedores tendem a mobilizar sua rede social para obter informações para acessar recursos e transformar visões e planos de negócios em realidade (BIRLEY, 1985). Se a rede social dos empreendedores, construídas pelos contatos formais e informais, contribuem para o alcance dos seus objetivos, estas redes são seu capital social. (BURT, 1992; PUTNAM, 1995). Este estudo tem como objetivo compreender como as redes sociais são utilizadas pelos empreendedores na formação do seu capital social, nas fases de criação e de desenvolvimento de um negócio. Realizou-se um estudo qualitativo de caso único em uma empresa do setor turístico localizada na região norte pioneiro do Paraná. As evidencias foram coletados por meio de entrevistas semi-estruturadas com os empreendedores além de observação simples e análise de documentos. Os resultados do trabalho sugerem que nas duas fases dos negócios; na criação e desenvolvimento, a rede social dos empreendedores permitiu acesso aos diferentes recursos que contribuíram para a formação do seu capital social.
\end{abstract}

Palavras- chave: Redes sociais; capital social; empreendedorismo; turismo.

\begin{abstract}
In new businesses creation entrepreneurs tend to mobilize its social networks to get information to access resources and to transform business vision and plans into reality (BIRLEY, 1985). If the social networks of the entrepreneurs, constructed by formal and informal contacts, contributes to reach entrepreneurs objectives, these networks are their social capital (BURT, 1992; PUTNAM, 1995). This study has as objective to understand how social networks are used by the entrepreneurs in the formation of their social capital, in the creation and development stages. A qualitative case study was carried out in a tourism business located in the pioneer north part of Paraná. Evidences were collected through semistructured interviews with the entrepreneurs and in additional simple observation and document analysis. The results of the work suggest that in the two phases of the business,

\footnotetext{
${ }^{1}$ Mestre em Administração pela Universidade Federal do Paraná. E-mail: norma@onda.com.br

${ }^{2}$ Professora do Departamento de Administração e do Mestrado em Economia (NUPEC) da Universidade Federal de Sergipe; Doutora em Administração pela Cranfield University - Inglaterra; Pós-Doutorado em Gestão do Turismo na Bournemouth University, Inglaterra e na Strathclyde University - Escócia; Pós-Doutorado em Empreendedorismo em Turismo na HEC em Montreal, Canadá. E-mail: rivandateixeira@terra.com.br
} 
creation and development, entrepreneurs social networks granted access to different resources that contributed to the formation of their social capital.

Keywords: Social networks; social capita; entrepreneurship; tourism.

\section{Introdução}

Considerando que a literatura sobre rede empresarial aponta que as redes sociais empresariais são relacionadas de forma positiva com o desempenho de uma empresa ou, para ser mais específico, sua sobrevivência e crescimento futuro dependem delas (ALDRICH; ROSEN; WOODWARD, 1987; GREVE; SALAFF, 2003; JOHANNISSON，1986; OSTGAARD; BIRLEY, 1996), busca-se evidenciar o importante papel do capital social dos empreendedores de negócios gerados pelas suas redes sociais.

No decorrer da criação e do desenvolvimento de novos negócios, os empreendedores tendem a mobilizar sua rede social para obter informações úteis, confiáveis e, às vezes, exclusivas, para acessar recursos e transformar visões e planos de negócios em realidade (BIRLEY, 1985). Eles criam negócios de sucesso, quando maximizam as oportunidades e, assim, as redes sociais são cruciais para os donos de negócios (BIRLEY; CROMIE, 1988).

Durante o processo de início de um novo negócio, o empreendedor está procurando não somente recursos de equipamentos, local de instalação e dinheiro, mas também conselhos, informações e confiança (BIRLEY, 1985). Esta ajuda e orientação podem ser obtidas através das redes sociais que podem ser formais e informais, de empresas ou individual, pessoal ou organizacional. Segundo Aldrich e Elam (1997) novos empreendimentos são criados, como resultado da motivação que os empreendedores ganharam quando tiveram acesso a recursos e descobriram novas oportunidades de negócios. Assim, desde o início de um empreendimento, a rede social destaca-se como fator muito importante para os donos de empresas. Mas o desenvolvimento de relações não é importante somente para fundar um empreendimento ou para o seu sucesso, elas também impactam no contínuo desenvolvimento da empresa.

Se a rede social dos empreendedores contribui para o atingimento dos objetivos empresariais, ou seja, quando as redes sociais, construídas pelos contatos formais e informais, contribuem para o alcance dos objetivos dos empreendedores, estas redes são seu capital social. (BURT, 1992; PUTNAM, 1995). 
Partindo desse pressuposto, o objetivo central deste estudo é analisar como as redes sociais são utilizadas pelos seus empreendedores na formação do capital social, nas fases de criação e de desenvolvimento do negócio, no contexto de uma empresa do setor turístico localizada na região norte pioneiro do Paraná. Especificamente vai identificar os tipos de redes sociais que são utilizadas por seus fundadores e, além disso, analisar como essas redes influenciam na obtenção de recursos financeiros, físicos e sociais.

\section{Redes Sociais Empreendedoras}

Redes podem ser visualizadas como uma série de relacionamentos dinâmicos estabelecidos pela troca de idéias, informações, mercadorias, poder e amizade (TICHY et al., 1979, apud ALDRICH; ZIMMER, 1986). Por sua vez, as redes sociais provêem fontes para aquisição de escassos meios, tais como; capital e informação (PORTES, 1995, apud LI, 2004) ou apoio para a idéia de que a rede de indivíduos pode tirar proveito de oportunidades em áreas nas quais eles não tenham nenhum especialista direto (ALDRICH; ZIMMER, 1986; OSTGAARD; BIRLEY, 1996).

A preocupação com o assunto rede social e sua relação com os empreendedores tem-se destacado em pesquisas e esta interação tem sido reconhecida como determinante do processo empreendedor, como também do sucesso dos empreendimentos. (ALDRICH; ROSEN; WOODWARD, 1987; GREVE; SALAFF, 2003). Quando os empreendedores usam as redes sociais para suportar as atividades de negócios temos as redes sociais empreendedoras.

A imagem popular do empreendedor como figura isolada que supera obstáculos e afasta os perigos sozinho, não existe. No domínio econômico é comum desencadearem-se relações de amizade e de confiança mútua entre empreendedores ou indivíduos (OSTGAARD; BIRLEY, 1994) quando desenvolvem a sua atividade econômica em determinado setor, numa região ou num país. Em conversas ou contatos informais empreendedores trocam informações sobre oportunidades de negócios, solicitam opiniões sobre tendências do mercado e pronunciam-se sobre a realidade econômica e social do país ou região onde intervêm. Em algumas das decisões empresariais tomadas é mesmo visível a influência exercida pelo seu grupo de pares ou pela sua rede social. 
As redes sociais empreendedoras são definidas como relações e contatos dos empreendedores com outras pessoas. Tais contatos fornecem meios para reconhecer oportunidades, obtenção de recursos como também facilidade de utilização de outros recursos, que são potenciais fontes de vantagem competitiva. (BARNIR; SMITH, 2002; BIRLEY, 1985).

O ponto de partida para o estudo de empreendedorismo através de redes sociais é a relação ou transação entre duas pessoas (ALDRICH; REESE; DUBINI, 1989). A teoria de rede social está relacionada com empreendedorismo como um processo empreendedor pelo qual os empreendedores procuram oportunidades sem levar em conta os recursos que eles controlam atualmente (STEVESON; JARILLO, 1990, apud LI, 2004) envolvendo o agrupamento de recursos escassos de suas redes de relacionamentos (BIRLEY; CROMIE, 1988). Birley (1985) cita que as redes sociais são muito importantes no processo inicial de empreendedorismo e que tipos de redes devem ser desenvolvidas de uma maneira tão proativa como as necessidades estratégicas e funcionais desenvolvidas pela organização.

As redes sociais empreendedoras são descritas de diferentes formas ou tipos em diferentes estudos. O que predomina nestes estudos é a força das ligações (ligações fortes e fracas), um tipo de rede baseado no indivíduo (LI, 2004). Alguns autores, tais como Ahmad, 2005, Sjöstrand(1992 apud LI, 2004); Johannisson, 1998; Ibarra, 1993, Ribeiro e Santos, 2003; mencionam em seus estudos que as redes entre empreendedores podem ser divididas em redes pessoais e redes de negócios, baseados no indivíduo e na organização. Há também estudos que ressaltam somente os diferentes tipos de redes de negócios segundo o ponto de vista organizacional.

Para Granovetter (1973), na análise das estruturas de redes, conceito fundamental é o de laço ou ligação e suas características. As ligações são importantes, porque além de caracterizarem a estrutura da rede, possibilitam que esta seja usada para o estudo de fenômenos, como difusão, mobilidade e coesão social. As ligações fortes existem quando há um pequeno grupo com relacionamentos longos, tais como membros da família e um grupo pequeno de conselheiros internos do dono do negócio. Elas são caracterizadas pelos investimentos pesados no relacionamento, contato freqüente com a outra pessoa e senso implícito de reciprocidade (COHOON; ASPRAY, 2007). Essas ligações fortes com familiares e amigos íntimos ou próximos são baseadas nas relações de confiança que geralmente são de benefício mútuo para ambas as partes Já as ligações fracas são de curta duração, de menor freqüência de 
contato, de menor confiança e mais ambigüidade de relacionamento. Podem ser consideradas como canais através dos quais idéias socialmente distantes, influências ou informações chegam ao indivíduo. Podendo diminuir informações redundantes e trazer informações novas aos agentes mais rapidamente. (GRANOVETTER, 1973, 1985).

Segundo Greve e Salaff (2003) o acesso a recursos depende de diferentes fases de um empreendimento, assim, com base nesta afirmação, estes autores realizaram um estudo e consideraram em sua pesquisa as três fases de estabelecimento de uma empresa: a de estudo da oportunidade, identificada como de motivação; a de planejamento do empreendimento e a do estabelecimento do empreendimento. O processo de mobilizar relacionamentos para acessar recursos é dinâmico e, portanto, tende a variar ao longo do desenvolvimento do negócio (LICHENSTEIN; BRUSH, 2001, apud VASCONCELOS et al., 2006). Assim, também entendendo o empreendedorismo como processo evolucionário, nesta pesquisa será considerado o acesso a recursos através das redes sociais, em duas fases do empreendimento, tal como as etapas definidas no trabalho de Vasconcelos et al. (2006); a de criação e a fase de desenvolvimento de novos negócios.

De forma geral, é sugerido que no decorrer da criação e do desenvolvimento de novos negócios, os empreendedores tendem a mobilizar sua rede de relacionamentos para acessar recursos e transformar visões e planos de negócios em realidade (BIRLEY, 1985; ALDRICH; ZIMMER, 1986; JOHANNISSON, 1998, 2000). De certa forma os empreendedores são relativamente dependentes de suas relações pessoais para obter recursos escassos (ALDRICH; ZIMMER, 1986; HANSEN, 1995) que muitas vezes não são adquiridos facilmente.

\section{Capital Social}

Para Borges (2007) a definição operacional de capital social empreendedor é que o capital social empreendedor designa as redes de relações externas dos empreendedores mobilizadas para a criação de um empreendimento. $\mathrm{O}$ autor ainda cita que paralelamente a Bourdieu (1986), a Coleman (1988) e Putnam (2000), outros autores, como Granovetter (1973, 1985); Lin (2001a, 2001b), conduzem estudos e utilizam alguns conceitos próximos, como exemplo, rede social ou recursos sociais e que muitos destes autores têm sido incorporados entre os pesquisadores que trabalham com o conceito de capital social. 
Lin (2001b) declara que a noção de capital social como investimento em relações sociais espera retorno, capital social é visto como o benefício que pode ser derivado da rede social. É neste sentido que também Recuero (2004) entende o capital social, este se constitui no conteúdo das relações sociais em uma rede, ou seja, trata-se do conteúdo embutido nas interações que constituem os laços sociais, que podem ser acumulados, aprofundando um determinado laço e aumentando o sentimento de grupo.

A idéia principal do conceito de capital social é que a rede social (ex. famílias, amigos e conhecidos) tem valor (PUTNAM, 2000). O capital social é produzido pela estrutura das relações sociais e pode ser mobilizado para facilitar ações (ADLER; KWON, 2002), sendo a sua adequação uma importante característica, fato que um tipo de rede social pode ser freqüentemente usado para diferentes propósitos.

Adler e Kwon (2002) mencionam duas perspectivas maiores dentro dos estudos que utilizam o conceito de capital social: perspectiva externa (quando a atenção é colocada nas relações externas de um ator) e a perspectiva interna (quando a atenção é colocada nas relações internas de um grupo ou de uma comunidade). Nota-se que existe outra terminologia para nomear as perspectivas externas e internas: perspectiva bridging e perspectiva bonding. Alguns autores pertencem ao primeiro grupo da perspectiva externa (BORDIEU, 1986; PORTES,1998), outros, pertencem ao grupo da perspectiva interna (PUTNAM, 2000; COLEMAN, 1988) e ainda tem os que abordam as duas perspectivas (NAHAPIET; GHOSHAL ,1998).

Segundo Nahapiet e Ghoshal (1998), o capital social é multidimensional, e ocorre nos níveis individual e organizacional. Esses autores enfatizam que o capital social comporta três dimensões relacionadas: a dimensão estrutural (ligações e configurações da rede), a dimensão relacional (a confiança, as normas, obrigações e a identificação com o grupo) e o aspecto cognitivo (as representações e interpretações compartilhadas).

Para Adler e Kwon, (2002), a amplitude do conceito capital social reflete uma característica primordial de vida social, a saber, que ligações sociais de um tipo (ex. amigos, família), freqüentemente podem ser usadas para diferentes propósitos (ex. suporte moral e material, conselhos relacionados e não relacionados a trabalho). Para os autores, o capital social que depende da capacidade de interação dos indivíduos envolvidos nas redes sociais pode ser considerado um diferencial para o sucesso do negócio, uma vez que contribui para abrir 
caminhos no momento em que oferece e multiplica as possibilidades advindas das informações e dos conhecimentos das pessoas que fazem parte desta rede, diminuindo os riscos e aumentando as oportunidades.

O capital social é gerado em grande parte pelas redes pessoais e profissionais do indivíduo, e ele pode ajudar o empreendedor de diferentes maneiras. A criação de um negócio não está baseada somente nos elementos chaves tradicionais como trabalho e tecnologia, mas também em ativos sociais que são comumente chamados de capital social (BÖGENHOLD , 2002). Não é somente o lucro que o capital social pode oferecer ao indivíduo ou ao grupo; para Borges (2007) entre as contribuições mais importantes, estão as informações ou conselhos, a formação e a apresentação as outras pessoas. Um capital social impróprio ou limitado pode igualmente constituir uma barreira de ação para o ator.

\section{Metodologia}

A estratégia de pesquisa escolhida para este estudo foi o estudo de casos, pois permite o entendimento do fenômeno como um todo, com profundidade. Segundo Yin (2001, p.32), o estudo de caso é "uma investigação empírica que investiga um fenômeno contemporâneo dentro de seu contexto da vida real, especialmente quando os limites entre o fenômeno e o contexto não estão claramente definidos". Exigem-se, também, nesse caso, numerosas fontes de dados para triangular as informações (TRIVINOS, 1987).

Como a entrevista é uma das técnicas de maior flexibilidade e uma das mais importantes fontes de evidência para um estudo de caso (YIN, 2001), foram realizadas entrevistas com os sócios empreendedores da empresa turística escolhida como o caso do estudo, com a duração média de duas horas cada uma, nos meses de julho e agosto de 2008. Todas as entrevistas foram gravadas e posteriormente transcritas e analisadas. Trivinos (1987, p. 148) recomenda a gravação da entrevista porque permite contar com todo o material fornecido pelo informante, o que não ocorre seguindo outro meio.

Embora as entrevistas constituam fonte essencial de informações para um estudo de caso, Yin (2001) recomenda corroborar os dados obtidos com outras fontes de evidências. Assim, foi realizada a observação simples e a análise de documentos. Foram observadas as instalações físicas das empresas, a equipe de funcionários e o funcionamento operacional dessas 
empresas. Alguns dos documentos utilizados neste trabalho foram documentos administrativos, relatórios e folders formulados pelas empresas pesquisadas, além de informações sobre essas instituições disponíveis em matérias publicadas na mídia: reportagens em jornais e internet.

As categorias analíticas do estudo foram definidas com base na revisão teórica e foram divididas em dois blocos: 1) os tipos de redes sociais para a criação e o desenvolvimento do negócio que são as formais e as informais 2) os recursos acessados pelos empreendedores como os recursos sócias, físicos e financeiros. Várias perguntas abertas foram realizadas com bases nas categorias e nos elementos de análise que estão detalhados no quando 1 .

Quadro 1- Categorias Analíticas e Elementos de Análise

\begin{tabular}{|c|c|}
\hline $\begin{array}{l}\text { Categorias } \\
\text { Analíticas }\end{array}$ & Elementos de Análise \\
\hline $\begin{array}{c}\text { Tipos de redes } \\
\text { sociais para a } \\
\text { criação e o } \\
\text { desenvolvimento do } \\
\text { negócio } \\
\end{array}$ & $\begin{array}{l}\text { Formais - Pessoas que mantêm ligações diretas ou assuntos referentes a } \\
\text { negócios (bancos, contadores, advogados, consultores e organizações). } \\
\text { Informais - Envolvem família, amigos, antigos colegas e empregados } \\
\text { (BIRLEY,1985). }\end{array}$ \\
\hline \multirow[t]{3}{*}{ Recursos Acessados } & $\begin{array}{l}\text { Recursos Sociais } \\
\text { Suporte emocional, moral e técnico; Identificação de novas oportunidades de } \\
\text { negócio e ameaças; Suporte motivacional; Reputação; Legitimidade; } \\
\text { Relação de Confiança; Status; Fonte de idéias e informações; Conselhos; } \\
\text { Compartilhamento de conhecimento e experiências entre atores envolvidos; } \\
\text { Indicações de fornecedores, clientes e funcionários pelos contatos } \\
\text { intermediários; } \\
\text { Capacidade ou habilidade adquiridas ou fortalecidas; } \\
\text { (ALDRICH; ROSEN; WOODWARD, 1987;ALDRICH; CARTER, 2004; } \\
\text { ALDRICH; ZIMMER, 1985; OSTGAARD; BIRLEY, 1994; HITE, 2001; } \\
\text { BIRLEY, 1985; JOHANNISSON, 1998; COOPER, 2000;SHAW; } \\
\begin{array}{l}\text { CONWAY, 2000; LIN, 2001b, BARNIR; SMITH, 2002; ADLER R; } \\
\text { KWON, 2002; VASCONCELOS, 2004; BORGES, 2005, 2007) }\end{array}\end{array}$ \\
\hline & $\begin{array}{l}\text { Recursos Financeiros } \\
\text { Empréstimos e financiamentos; orçamento; procura por investimentos; } \\
\text { aplicação dos recursos; custos fixos (matérias-primas e fornecedores, } \\
\text { equipamentos, locações e funcionários). (BIRLEY, 1985; BARNEY, 1991, } \\
\text { 1995; CHU, 1996; BORGES, 2007). }\end{array}$ \\
\hline & $\begin{array}{l}\text { Recursos Físicos } \\
\text { Matérias-primas e insumos, máquinas e equipamentos, veículos, imóveis e } \\
\text { localização física (VASCONCELOS,2004). }\end{array}$ \\
\hline
\end{tabular}

Fonte: Desenvolvido com base na revisão teórica 


\section{Análise do Caso da Empresa de Turismo - Laram Turismo}

A Laram Turismo foi criada, em 2001, pelo casal Reinaldo e Leomara. É especializada em organizar viagens de férias ou de negócios para qualquer parte do Brasil e do mundo. Trata-se de uma agência de turismo, um agente credenciado da CVC, da venda de cruzeiros marítimos, locação de veículos e assessoria em eventos, que hoje tem cinco funcionários, incluindo os sócios, dois dos quais ficam locados exclusivamente na agência da cidade de Cambará e um na agência de Cornélio Procópio, tendo como missão oferecer segurança e especialidade em seus serviços, vendendo passagens aéreas e rodoviárias, reserva de hospedagem, pacotes turísticos nacionais e internacionais. Atualmente trabalham com pacotes turísticos rodoviários, uma média de quinze por ano, e, ainda, diferentes pacotes turísticos aéreos que geram uma média de 500 contratos anuais, variando de três a quatro clientes por contrato. Sua base de clientes, atualmente, é de 2000 clientes, pertencentes a 70 cidades de diferentes estados brasileiros: São Paulo, Mato Grosso do Sul, Rio de Janeiro e Paraná. Leomara tem 37 anos, é formada em Administração de Empresas, com pós-graduação em Gestão Empresarial em Turismo, e Reinaldo, 47 anos, é também graduado em Administração de Empresas. Antes de abrir o próprio empreendimento, trabalhou por muitos anos em um banco estadual, em diferentes agências do Paraná; Cornélio Procópio, Andirá, Joaquim Távora e Cambará. Atualmente, a matriz da agência de turismo está localizada na cidade de Cambará, e sua filial na cidade de Cornélio Procópio.

\subsection{A fase de criação do novo negócio}

Em outubro de 2000, Reinaldo, gerente de um banco da cidade de Cambará, resolveu realizar uma viagem a passeio para o nordeste com sua esposa e casais de amigos. Procurando um pacote para a viagem tiveram com uma grande dificuldade: encontrar uma agência de viagem na cidade em que moravam ou nas cidades vizinhas, que ajudasse a planejar o roteiro desejado, satisfazendo suas necessidades. Mesmo assim, fecharam o pacote de viagem com a agência credenciada $\mathrm{CVC}$ da região, mas como não acharam um pacote completo que incluísse os roteiros e os passeios desejados, compraram um pacote simples e se dispuseram a incrementar o roteiro básico proposto. Assim, através da internet estudaram todo o roteiro a ser realizado, entraram em contato com diversos prestadores de serviços da região de destino e organizaram a sua viagem detalhadamente. Muitas foram as providências necessárias para a 
realização da viagem, desde a contratação de um meio de transporte para deslocamento até a cidade de embarque, até negociações de preços dos passeios e translado para aeroportos.

Foi com a experiência desta viagem que o casal identificou uma oportunidade de negócio na cidade, inicialmente ligada à prestação de serviços de transporte. Devido à carência existente neste tipo de serviço, Reinaldo convidou um amigo com quem trabalhava no banco para uma sociedade na compra de uma van com o objetivo de prestar serviços de transporte. Esse sócio convidado entrou, de fato, só com o capital, ou parte dele, pois Reinaldo e Leomara foram os responsáveis pela administração e gerenciamento do novo negócio. A idéia original do negócio era prestar serviços de transportes intermunicipais, mas, posteriormente a idéia era realizar viagens turísticas nos finais de semana. Com a aquisição da van, contrataram um motorista, segundo Reinaldo, indicado por seu sócio. "Foi uma boa indicação. Ele era um motorista muito responsável e comprometido".

Mas aconteceram transformações econômicas nessa época. O banco no qual Reinaldo trabalhava foi privatizado e ele não se adaptou ao estilo de gestão do banco privado. Começou, então, a pensar na possibilidade de mudar de emprego. Discutiu a idéia com a esposa e tomou a difícil decisão de participar do primeiro PDV (Pedido de Demissão Voluntária) oferecido pelo banco. Com o dinheiro recebido iria montar um negócio; talvez um posto de gasolina.

Como moravam em uma cidade pequena, Cambará, conheciam e tinham contato com a maioria da população. Foi dessa forma que começaram a prestar atenção às solicitações e reclamações sobre a falta de transporte escolar e detectaram, então, a necessidade de criar uma linha de transporte para atender os estudantes da cidade e da região que estudavam nas cidades vizinhas (Marília, Jacarezinho). Foi pensando na expansão de seu negócio que, em 2001, Reinaldo comprou um microônibus, incrementando, assim, a frota de veículos e tendo de contratar mais um motorista.

Para prestar tal serviço, houve necessidade de constituir e criar legalmente uma empresa e, assim, nasce, em 2001, a Transporte Turístico RA Martins, transportadora turística, cujas instalações ficavam na própria casa do casal. A empresa ficou ativa até 2007, fazendo o transporte de clientes diversos para diferentes destinos e roteiros turísticos. Assim, durante a semana usavam os transportes para viagens intermunicipais com estudantes e nos fins de 
semana começaram a realizar alguns pacotes de viagens de turismo, tentando responder às necessidades de alguns clientes interessados.

Ainda em 2001, o negócio foi se ampliando e a empresa, além de serviços de transportes, passou a atuar mais intensivamente na área de turismo. Nessa época, a pequena frota de veículos era, até então, guardada no terreno vizinho à empresa, o qual era, também, utilizado pelo banco como estacionamento. Desta forma, não havia necessidade de pagar pelo aluguel. Com o crescimento do negócio, cresceu também a preocupação em satisfazer às solicitações dos clientes já conquistados e os que pretendiam conquistar. Definiram, então, as formas diferenciadas de vender e atender os clientes, como Leomara destaca: "como começamos a promover excursões e pacotes de viagens, passamos a ficar atentos a todos os tipos de comentários e necessidades dos clientes, na tentativa de descobrir novos mercados e oportunidades".

Como optou por sair do emprego do banco, em 2001, Reinaldo não estava certo de que tinha tomado a melhor decisão, em razão da instabilidade da atividade empresarial. Ele conta como esse momento foi difícil e destaca a importância do apoio da esposa na decisão:

Foi uma decisão muito difícil. Eu sofria um conflito interno pelo fato de deixar um emprego seguro. Muitas pessoas me falavam que eu estava ficando louco, que poderia ser uma aventura perigosa. Mas eu e a minha esposa conversamos muito, e ela apoiou a minha decisão. Ela também estava disposta a arriscar. Queríamos ter nosso próprio negócio (REINALDO).

Decidiram não comprar um posto de gasolina, mas sim investir na compra de mais um veículo para a frota. Compraram, então, um ônibus com parte dos recursos próprios e outra parte financiada pelo próprio banco onde trabalhou.

Acho que foi a única vez que solicitamos empréstimo. Eu acho que tendo capital próprio, acaba não tendo despesa financeira, porque se você vai pegar dinheiro no mercado, o custo desse dinheiro, no mercado hoje, é muito grande; [...], é claro que tivemos algumas dificuldades no passado, mas nunca pegamos dinheiro emprestado. Sempre seguramos com capital próprio, porque os juros são muito altos e não permitem isso (REINALDO).

Como Reinaldo não tinha mais vínculo com o banco, passaram a utilizar o pátio de um posto de gasolina de um amigo, como estacionamento. Pelo fato de abastecerem e utilizarem os 
serviços desse posto, não precisavam pagar por esse serviço. Com o aumento da frota e com a dedicação exclusiva do Reinaldo ao negócio, os empreendedores sentiram-se mais motivados e passaram a se dedicar ainda mais aos pacotes turísticos e às excursões. Estabeleceram como objetivo proporcionar bens e serviços diferenciados que satisfizessem as solicitações dos clientes. Percebiam a importância dos relacionamentos nas redes sociais, conforme explicou Reinaldo:

Notamos o quanto era importante para o sucesso do nosso negócio ampliar nossos relacionamentos, círculos sociais, interagir com pessoas e organizações deste ramo de negócio, para aumentar conhecimentos e trocar experiências (REINALDO).

Para conseguir uma maior aproximação com os clientes, decidiram que, nas viagens promovidas pela RA Martins, pelo menos um dos dois (Reinaldo ou Leomara) acompanharia as viagens, pois assim teriam a oportunidade de conhecer os novos destinos, identificar as melhores opções de serviços, desenvolver novas parcerias e ainda conhecer melhor seus clientes, descobrindo e entendendo melhor suas necessidades e desejos, como destaca Reinaldo: "como um de nós sempre acompanhava as viagens planejadas e montadas pela Laram, mantínhamos contato direto com os clientes e isso foi abrindo várias portas e proporcionando muitos novos negócios."

Pelo sucesso que vinham obtendo com a realização dos pacotes de viagens, pensaram na possibilidade de também criar uma agência de viagens, ou seja, de criar um outro empreendimento. Assim, optaram pela realização de uma pesquisa que ajudasse a identificar o mercado de turismo na região. Pelos resultados obtidos, decidiram pela criação de uma agência de turismo. Nesta fase, um contato muito importante destacado foi o que mantiveram com a filha de um amigo, Ana, turismóloga em Curitiba, com quem conversaram para trocar idéias sobre o que precisariam para abrir uma agência de turismo. De acordo com Leomara, esse contato foi fundamental nesse momento: "Ela conversou bastante conosco, deu muitas idéias, dicas e passou as principais diretrizes que foram importantíssimas para nós. Também nos incentivou muito para a abertura do negócio”. Nesse ano, Reinaldo buscou aprimorar seus conhecimentos sobre a criação de negócios, como explica:

Eu participei de alguns cursos para empreendedores, oferecido pelo SEBRAE. Fiz o curso EMPRETEC e, na realidade, estabeleci uma rede de relacionamentos com 
alguns consultores, o que me proporcionou uma consultoria sem custo para a realização do estudo de mercado para a obtenção e autorização do funcionamento junto à EMBRATUR (REINALDO).

Os empreendedores iniciaram o estudo para a criação de uma agência de turismo que seria localizada na cidade de Cornélio Procópio, cidade na qual moraram anos atrás antes de Reinaldo ser transferido pelo banco. Mas, analisando o mercado, identificaram a existência de três agências na cidade e, então, resolveram abrir sua agência em Cambará. Definida a cidade, começaram a providenciar todos os documentos necessários para a formalização da empresa e contrataram um escritório de contabilidade. Mas, como se tratava de um tipo de negócio novo para os responsáveis pelo escritório de contabilidade, os empreendedores receberam uma orientação incorreta na abertura da empresa e, por um ano, realizaram recolhimentos desnecessários de impostos, bem como emitiram notas fiscais incorretas. Depois de um ano de funcionamento da empresa, os responsáveis pelo escritório reconheceram o erro, conforme relata Reinaldo: "até hoje trabalhamos com o mesmo escritório contábil. Na realidade, nesta parceria ambos aprendemos sobre o negócio de prestação de serviços".

Em 2001, foi criada, então, a outra empresa, a Laram Turismo. Com uma agência de transportes e uma agência de turismo, decidiram mudar as instalações, que agora comportariam as duas empresas. Mas, na realidade, não havia uma separação em termos de negócios entre as duas empresas; somente legalmente. Falando de rede de relacionamento, Leomara relata que pelo fato de Reinaldo fazer parte do Lions Clube, a Laram foi selecionada pelos membros desse clube para organizar um pacote de viagem (hospedagem, alimentação, passeios, transportes, etc.) para levar quarenta pessoas à Convenção do Lions, que naquele ano ocorreu em Gramado-RS. "tivemos uma ajuda muito grande da secretária do distrito do Lions que ajudou a divulgar a viagem para os outros clubes da região, e ajudou na venda dos pacotes".

Como a cidade de Cambará era pequena e possuía poucos pontos comerciais atraentes para abertura de um negócio, os empreendedores tiveram dificuldades em encontrar um imóvel adequado para alugar. Foi através de uma vizinha que conseguiram chegar até o proprietário do imóvel onde a Laram Turismo ficou instalada por quatro anos. Nessa negociação, destacase um recurso social que foi acessado graças ao fato do Reinaldo ter trabalho no banco e ser 
muito conhecido na cidade, como explica: Quando eu fui conversar com o dono do imóvel, ele sabia quem eu era e sabia que eu trabalhava até pouco tempo como gerente do banco, e, assim, eu notei que isso teve certa influência no momento da contratação do local.

Com a abertura da nova empresa, contrataram uma funcionária para ajudar na parte administrativa. A contratação dessa funcionária foi realizada pela amizade que Reinaldo mantinha, pois era uma ex-companheira de banco e atuava como telefonista. Nessa época, segundo os empreendedores, a Laram Turismo era uma empresa com um perfil mais de prestadora de serviços de transporte rodoviário. Foi pensando em atender solicitações de clientes com pacotes turísticos para regiões mais distantes, como o Nordeste, que começaram a mudar o foco. Decidiram realizar novas parcerias, com novas operadoras, incluindo pacotes aéreos, destaca Reinaldo:

Direcionar a empresa para a satisfação do cliente, significa entender a qualidade do ponto de vista do cliente; significa identificar os valores mais importantes que proporcionam maior satisfação. Serão elementos orientadores da estratégia da empresa, tanto para atuar no ambiente externo, como para organizar sua estrutura interna (REINALDO).

Iniciaram novos roteiros de viagem e, algumas vezes, por terem pouco conhecimento do setor, nem sempre conseguiram resultados positivos. Somente com o tempo e com muito trabalho, estabeleceram parcerias que atendiam à qualidade desejada e necessária para os clientes da Laram Turismo. Reinaldo relata: "Nos primeiros pacotes turísticos por via aérea, os dois iam juntos para fechar o número mínimo de pessoas, o que propiciou a oportunidade de conhecermos novos lugares.” Assim, expandiram as opções de pacotes turísticos. Dessa fase, Leomara resgata um importante relacionamento estabelecido com uma funcionária de uma operadora de turismo de Curitiba, conforme relata: "Cláudia, da Turiskente, nos ensinou e deu dicas boas de pacotes de viagens para Pousada do Rio Quente. Ela simulava descontos, fazia os diferentes cálculos e nós mantínhamos um contato bem freqüente com ela”.

Ainda em 2001, a CVC operadora turística instalou em Londrina uma filial e junto com esta filial, começaram a negociar alguns pacotes turísticos. Assim, iniciaram um relacionamento com a operadora, que é mantido até hoje e foi evoluindo, a cada ano, de forma positiva, segundo o comentário de Leomara: 
Nesta época surgiu a dúvida sobre qual a melhor operadora para a Laram estabelecer parceria: a operadora CVC ou a agência Soletur, já instalada em Londrina. Como nossa viagem em 2001 foi realizada pela CVC e alguns dos seus serviços já conhecíamos, então escolhemos esta empresa. Acho que demos sorte, pois com a ação terrorista de 11/09/2001, a Soletur quebrou e muitos parceiros desta também. Temos um relacionamento muito bom com esta operadora. É uma parceria que tem dado certo (LEOMARA).

Outro relacionamento importante mencionado por Leomara é o mantido com Andréia, supervisora da CVC, que lhes proporcionou a oportunidade de conhecer melhor o setor de turismo. Os dois empreendedores comentam sobre a importância dessa relação:

Nós aprendemos muito deste ramo de negócio com a Andréia. Ela nos ajudava a fechar os pacotes, realizar os cálculos para negociações, nos ensinava muito da linguagem técnica desta área de negócios. Ela praticamente prestava consultoria para nós nesta área. Nos direcionava nos aspectos legais e financeiros relacionados aos pacotes de viagens contratados (LEOMARA).

Além da Andréia, Leomara comentou que a CVC tinha outros supervisores, mas a proximidade com a Andréia e a confiança recíproca foram fundamentais para a aprendizagem e o crescimento do negócio.

Sempre consideramos importante manter um vínculo, ou laço mais forte com ela, pois com certeza isto gerou um retorno muito grande no nosso negócio. Sempre fechávamos a negociação com ela para ter certa intimidade e isso foi muito bom (LEOMARA).

Visando atingir o objetivo de fazer crescer o negócio, continuaram a investir na própria capacitação para este tipo de negócio. Leomara realizou um curso de pós-graduação em turismo para aprimorar seu conhecimento na área. Outro curso foi o de Guia de Turismo, que Reinaldo, Leomara e a assistente administrativa realizaram em Londrina, com duração de um ano. Os empreendedores ressaltam a importância do treinamento de seus funcionários, que também têm acesso direto aos clientes, atuando como uma apresentação da própria empresa. Leomara comentou: “eles ajudam a transmitir a imagem da empresa aos clientes." 
Os cursos e treinamentos realizados pelos empreendedores os ajudaram a estabelecer uma rede de contatos com os integrantes desses eventos e, mesmo após o término deles, muitos relacionamentos se mantiveram de forma intensa. Leomara comentou sobre como essas relações foram importantes para a empresa:

Houve uma grande troca de informação e idéias durante as aulas devido à rede de relacionamentos que foi desenvolvida com os alunos participantes. A maioria dos alunos tinha formação em turismo, e outros exerciam cargos ligados à área, como secretários de turismo das prefeituras da região. Esses contatos abriram muitas portas para a Laram (LEOMARA).

Destaca-se, nessa fase, a preocupação dos empreendedores em buscar aprender sempre mais para conhecer o setor turístico e o mercado em que estavam atuando, a fim de tornarem-se articulados com as demandas dos clientes.

\subsection{A fase de desenvolvimento do novo negócio}

$\mathrm{Na}$ fase de desenvolvimento, os empreendedores tinham bem alinhados os objetivos e metas do negócio e, por isso, optaram em fechar a RA Martins transportes. Decidiram vender toda sua frota de veículos devido ao alto risco que o negócio representava e pelo pequeno retorno em relação ao esforço despendido para sua manutenção. Optaram, então, por investir mais tempo e energia na agência de turismo Laram, conforme explica a empreendedora:

Por uma série de motivos, como alto custo com motoristas, acidentes ocorridos na estrada, risco alto de acidentes, nós optamos por nos dedicar apenas ao negócio Laram Turismo, sem mais nos preocupar com o nosso transporte, mas sim terceirizar estes serviços, uma vez que tínhamos desenvolvido muitos relacionamentos com prestadores de serviços nesta área (LEOMARA).

A empresa já estava localizada em um ponto mais estratégico da cidade e com situação estabilizada e se destacava na região. Outro recurso social que os empreendedores se lembraram de haver utilizado foi a escolha das novas instalações pela indicação de um conhecido deles para o representante de locação do imóvel. Um dos aspectos que os empreendedores disseram que diferencia a Laram Turismo das outras agências, era a forma de administrar e desenvolver seus pacotes de viagens, na maior parte das vezes fechados para os grupos. As viagens eram programadas para diferentes grupos, como membros de igrejas, 
colégios, amigos, associações de professores e aposentados de diferentes cidades da região que preferiam realizar as viagens juntos.

Temos vários grupos que viajam conosco há mais de cinco anos. Tem um grupo de amigos, por exemplo, que pelo relacionamento de longa data, atualmente nos repassa a data desejada e o valor disponível para realizar da viagem, e nós da Laram montamos algumas opções de destino e sugerimos (LEOMARA).

Os empreendedores percebem que o relacionamento com esses grupos de clientes se ampliou e que essa rede de relacionamentos se expandiu, uma vez que os clientes se mantiveram fiéis à agência e ainda proporcionaram novas oportunidades de negócios com outros clientes e a novos roteiros. Na percepção de Leomara, os relacionamentos desenvolvidos e mantidos por Reinaldo na época do banco, foram de fundamental importância desde a criação do negócio. Devido à posição que mantinha de gerente da agência do banco de uma cidade pequena, sempre teve acesso a clientes e funcionários de outras cidades e, graças a isso, muitos canais se abriram para a distribuição e oferta de seus pacotes turísticos.

Como o Reinaldo conhecia muita gente da região, era mais fácil oferecer e enviar nossos prospectos e folders de viagens. Muitas vezes nós ligávamos para as pessoas e então marcávamos uma visita para explicar e oferecer nossos produtos/serviços. Sem dúvida nenhuma, estes contatos do Reinaldo foram fundamentais para nós; proporcionaram uma abertura e ação direta com o cliente (LEOMARA).

O negócio estava se expandindo, mas foi em 2006, durante um Workshop em Londrina promovido pela operadora CVC, que se deram conta do tamanho e da importância de sua agência de turismo na região. Nesse evento, estavam reunidas várias redes hoteleiras de determinado estado, e o organizador do evento, num dado momento, parou ao lado da mesa onde estavam Reinaldo e Leomara, e apresentou a Laram Turismo como a quarta agência da filial de Londrina que mais vendia pacotes turísticos da CVC. Era uma posição de destaque, uma vez que foram consideradas todas as agências localizadas na região, por volta de 90 . Também foi classificada, segundo Leomara e Reinaldo, entre as vinte maiores agências credenciadas do Sul do Brasil, sendo a que mais vendia pacotes turísticos pela CVC: 
Esse fato teve uma repercussão muito boa para a agência, com reflexo na nossa própria cidade, onde muitas pessoas influentes que ficaram sabendo da nossa classificação ajudaram a disseminar nosso trabalho diferenciado. $\mathrm{O}$ fato aumentou a confiança na nossa reputação (REINALDO).

Quanto a novos relacionamentos, comentaram que anualmente participam de outros Workshops oferecidos pelas operadoras, hotéis e receptivos. Em alguns eventos, por exemplo, um estado turístico do Brasil é selecionado e então representantes de diferentes hotéis, agências, receptivos deste estado expõem seus produtos/serviços. Nesses eventos, são realizadas parcerias, negociações e, ainda, são oferecidos passeios, pacotes, hospedagens, jantares às agências de turismo, para estas avaliarem seus serviços e realizarem novos negócios.

Os empreendedores destacaram, também, a existência de eventos para toda a América, promovidos pela ABAV (Associação Brasileira de Agência de Viagens), ressaltando novamente que estes são muito importantes devido às relações desenvolvidas com as empresas de transportes e hospedagem, com restaurantes, shoppings, operadoras de transporte e, operadores e agências de turismo. A relação de parcerias foi destacada com algumas operadoras, tais como MGTravel, CVC, Personal Valitur, Gralha Azul, TIL Transportes. Geralmente contratavam pacotes aéreos com as operadoras de viagem e os pacotes rodoviários eram contratados com a Til Transportes.

Alguns desses relacionamentos foram mantidos desde a fase de criação da empresa, como é o caso da Til Transportes, no qual o contato com o gerente permitiu o acesso a diferentes informações financeiras e comerciais que direcionam cenários futuros nesta área.

Os entrevistados comentaram que as operadoras oferecem, anualmente, o FUNTUR, que são viagens oferecidas para os agentes conhecerem pontos turísticos e suas atrações. Estão incluídos nesse pacote a passagem, hospedagem, alimentação e, muitas vezes, viagem para Disney, cruzeiros com novos navios. Para Leomara, essa é uma forma de conhecer pessoas e criar redes de contatos: "estes relacionamentos mantidos com as operadoras são muito importantes, eles vão se ampliando e, desta forma, surgem oportunidades de negócios que nos ajudam a identificar e definir estratégias futuras". Para Reinaldo, essa rede favorece o seu cliente final: 
Pela rede de relacionamento desenvolvida e estabelecida com alguns parceiros, temos acesso a vários serviços e recursos que muitas vezes são repassados para os nossos clientes, tais como cortesias de coquetel de chegada, upgrade de apartamentos no caso de lua de mel, citytour sem custos. Assim, a Laram fideliza e agrada o cliente sem disponibilizar honorário (REINALDO).

Quanto à preocupação com o processo de manutenção dos clientes, Reinaldo diz “com a visão de atender o mercado não somente de forma reativa, geralmente procuramos diferenciar nossas ofertas de serviços/produtos." Percebe-se no empresário uma visão mais ampla de negócio, a busca por conhecimento do seu público-alvo e a preocupação por aperfeiçoar o atendimento:

Realizamos um monitoramente sistemático do mercado de forma a conhecê-lo mais profundamente e daí compatibilizar as ações com os desejos e necessidades dos consumidores. Acho que este é o principal diferencial competitivo no setor de serviços. Estamos sempre perto de nossos clientes. Nós vendemos nossos produtos/serviços diretamente para o consumidor final (REINALDO).

O acompanhamento formal dos clientes em suas viagens favorece a construção de uma rede de relacionamentos que é fundamental para a sobrevivência e desenvolvimento do negócio e constitui o seu diferencial. Em 2008, como tinham um número grande de clientes que habitavam em Cornélio Procópio, resolveram ampliar a carteira de clientes e abriram uma filial da agência Laram nessa cidade. Começaram, então, a pesquisar uma sala bem localizada para se instalarem e, mais uma vez, pela indicação de um amigo, tiveram acesso ao dono do imóvel que fica localizado na principal avenida comercial da cidade.

Com o objetivo de tornar mais claros os tipos de relacionamentos existentes e os diversos recursos utilizados pelos empreendedores o quadro 2, a seguir, apresenta o resumo desses relacionamentos e recursos na fase de criação do negócio e o quadro 3, na seqüência, mostra na fase de desenvolvimento da empresa. 
Quadro 2 - Tipos de redes e recursos utilizados na fase de criação do novo negócio

\begin{tabular}{|c|c|c|c|}
\hline Etapas & & & Redes \\
\hline & Tipos de redes & Informais & Amigos, vizinho, ex-colegas de trabalho e clientes. \\
\hline & & Formais & Operadoras e agências de turismo. \\
\hline & & & $\begin{array}{l}\text { Identificação de ocasiões de negócios, nos contatos com os } \\
\text { clientes. }\end{array}$ \\
\hline & & & Contratação de funcionário, pela indicação do sócio da Van. \\
\hline & & & $\begin{array}{l}\text { Obtenção de apoio moral e motivacional, dicas e idéias da filha de } \\
\text { um amigo, Ana, turismóloga em Curitiba. }\end{array}$ \\
\hline & & & $\begin{array}{l}\text { Acesso a um serviço de consultoria, sem custos, sobre pesquisa } \\
\text { de mercado, graças ao relacionamento que manteve com } \\
\text { consultores do Sebrae durante a realização do curso EMPRETEC. }\end{array}$ \\
\hline & & & $\begin{array}{l}\text { Uma das primeiras viagens realizadas pela agência foi decorrente } \\
\text { do fato do Reinaldo ser membro de um Clube de Serviços. }\end{array}$ \\
\hline & & & $\begin{array}{l}\text { Negociação junto ao proprietário de um imóvel a ser utilizado como } \\
\text { sede da empresa, facilitada pela indicação de pessoas do seu } \\
\text { relacionamento e pela posição gerencial que ocupava no banco. }\end{array}$ \\
\hline & & & $\begin{array}{l}\text { Contratação de funcionária para agência facilitada graças a } \\
\text { mobilização de contatos com uma ex-colega de trabalho. }\end{array}$ \\
\hline & & Sociais & $\begin{array}{l}\text { Facilidade nas negociações junto a uma pousada bastante } \\
\text { solicitada pelos clientes, em decorrência da mobilização de } \\
\text { contatos com a funcionária de uma operadora turistica. }\end{array}$ \\
\hline & & & $\begin{array}{l}\text { Informações e dicas valiosas, bem como orientações sobre como } \\
\text { conduzir o negócio "turismo", recebidas de uma funcionária da } \\
\text { CVC. }\end{array}$ \\
\hline Criação & & & Indicações de fornecedores importantes para o negócio. \\
\hline & Recursos Obtidos & & $\begin{array}{l}\text { Aumento do conhecimento técnico e teórico sobre o assunto } \\
\text { Turismo, através da realização de cursos e treinamentos. }\end{array}$ \\
\hline & & & $\begin{array}{l}\text { Acesso a novas idéias e novos tipos de serviços pelo contato } \\
\text { freqūente mantido com os clientes durante as viagens realizadas. }\end{array}$ \\
\hline & & & Obtenção de acesso a cursos e workshops. \\
\hline & & & $\begin{array}{l}\text { Mobilização de contatos da época da realização dos primeiros } \\
\text { cursos de turismo e de curso de pós-graduação. Alguns vínculos } \\
\text { até hoje são mantidos, inclusive para negócios. }\end{array}$ \\
\hline & & & $\begin{array}{l}\text { Pela indicação de ex-colegas de trabalho, tem acesso a novos } \\
\text { clientes. Um contato (cliente) indica novos contatos para a agência, } \\
\text { gerando por consequencia novos clientes. }\end{array}$ \\
\hline & & Financeiros & $\begin{array}{l}\text { Captação de recurso financeiro com um amigo que se tornou sócio } \\
\text { na aquisição de um veículo de transporte. }\end{array}$ \\
\hline & & & $\begin{array}{l}\text { Captação de recurso financeiro com o banco em que trabalhou } \\
\text { para a compra de outro veículo da frota. }\end{array}$ \\
\hline & & & $\begin{array}{l}\text { Por ser funcionário do banco, e empresa tinha acesso a um } \\
\text { terreno, ao lado do banco, que utilizavam como estacionamento } \\
\text { para os veículos da sua frota, sem custo. }\end{array}$ \\
\hline & & Fisicos & $\begin{array}{l}\text { Pelo fato de ser amigo do dono de um posto onde abastecia, } \\
\text { passou a guardar a frota de veículos no pátio desse } \\
\text { estabelecimento. }\end{array}$ \\
\hline & & & $\begin{array}{l}\text { Posicionamento do estabelecimento em local mais estratégico na } \\
\text { cidade, pela indicação de um contato. }\end{array}$ \\
\hline
\end{tabular}

Fonte: Desenvolvido pela pesquisadora com base na coleta de dados 
Quadro 3 - Tipos de redes e recursos obtidos na fase de desenvolvimento do novo negócio

\begin{tabular}{|c|c|c|c|}
\hline Etapas & \multicolumn{3}{|r|}{ Redes } \\
\hline \multirow{13}{*}{ Desenvolvimento } & \multirow{2}{*}{$\begin{array}{l}\text { Tipos de redes } \\
\text { desenvolvidas }\end{array}$} & Informais & Amigos, colegas de trabalho e clientes. \\
\hline & & Formais & Operadoras e agências de turismo. \\
\hline & & & $\begin{array}{l}\text { Fortalecimento dos laços de amizades com clientes cujo } \\
\text { relacionamento iniciou-se na fase de criação e se estende até a } \\
\text { fase atual. }\end{array}$ \\
\hline & & & $\begin{array}{l}\text { Acesso a serviços e recursos privilegiados dos parceiros que são } \\
\text { repassados para os clientes, tais como: cortesias de } \\
\text { apartamentos, passeios, café da manha, citytour }\end{array}$ \\
\hline & & & $\begin{array}{l}\text { Obtenção de acesso a cursos, eventos, workshops, viagens } \\
\text { oferecidos pelas operadoras de turismo, inclusive alguns sem } \\
\text { custos nenhum. }\end{array}$ \\
\hline & & & $\begin{array}{l}\text { Indicação da Laram, pela operadora CVC, como a quarta principal } \\
\text { agência/parceira da filial de Londrina, de um total aproximado de } \\
90 \text { agências. } \\
\text { E ainda, classificação entre as } 20 \text { maiores agências credenciadas } \\
\text { do Sul do Brasil. }\end{array}$ \\
\hline & & & $\begin{array}{l}\text { Mobilização de contatos da fase da criação do negócio gera novos } \\
\text { contatos e clientes na fase de desenvolvimento do negócio. }\end{array}$ \\
\hline & & & $\begin{array}{l}\text { Mobilização de contatos da fase da criação do negócio gera novos } \\
\text { contatos com fornecedores e novas parcerias na fase de } \\
\text { desenvolvimento do neqócio. }\end{array}$ \\
\hline & & & $\begin{array}{l}\text { Evolução da confiança com alguns parceiros desenvolvidos na } \\
\text { fase de criação a qual nesta fase, pelos contatos frequentes, se } \\
\text { intensificou. }\end{array}$ \\
\hline & & & $\begin{array}{l}\text { Contratação de uma funcionária para a nova agência, por indicação } \\
\text { da irmã de Reinaldo. }\end{array}$ \\
\hline & & & $\begin{array}{l}\text { Acesso a workshops promovido pela ABAV e também, a diversos } \\
\text { eventos ofercidos pelas operadores turisticas, as quais geram } \\
\text { sempre novos relacionamentos }\end{array}$ \\
\hline & & Financeiros & Não identificado \\
\hline & & Fisicos & $\begin{array}{l}\text { Pela indicação de um contato consegue acesso ao dono de um } \\
\text { imóvel de localização estratégica para a instalação da agência em } \\
\text { Cornélio Procópio. }\end{array}$ \\
\hline
\end{tabular}

Fonte: Desenvolvido pela pesquisadora com base nos dados coletados

\section{Conclusões}


Este estudo teve como objetivo compreender como as redes sociais são utilizadas pelos empreendedores na formação do seu capital social, nas fases de criação e de desenvolvimento de um negócio.

Conforme destaca Birley, Cromie e Myers (1990), as redes sociais baseiam-se em relacionamentos sociais, família, amigos, vizinhos, assim como em clientes, vendedores e credores. Alguns autores, como Johannisson (1998); Aldrich e Zimmer (1986); Aldrich e Dubini (1991), bem como Barnir e Smith (2002), destacam que os contatos têm como objetivo não só obter os recursos econômicos para iniciar o negócio, mas também buscar apoio para a idéia do negócio, conselhos e informações e suporte social e apoio emocional e moral para a constituição da empresa. Aldrich, Elam e Reese (1996) destacam que as redes sociais podem ajudar a obter clientes, tecnologia, fornecedores, recursos físicos, recursos financeiros, suporte motivacional e pessoal.

Na Laram Turismo, destacam-se os contatos estabelecidos pelos empreendedores com os excolegas de banco e com as funcionárias de operadoras de viagens, que lhes proporcionaram informações essenciais facilitadoras da compreensão do setor e do negócio. Alguns destes contatos se tornaram bastante freqüentes gerando fortes ligações. Destacou-se na fase de criação do negócio, o contato freqüente desenvolvido com a funcionária da operadora CVC, que ensinou aos empreendedores muitas das peculiaridades do negócio. A oportunidade de negócio foi percebida pela identificação de suas necessidades, ocorrida na primeira viagem, e depois, através das pessoas com as quais os empreendedores mantinham contatos, sua rede de relacionamentos. Logo na fase da sua criação, graças à indicação feita pelo Lions Club, a empresa pôde desenvolver um novo pacote para uma viagem, em grupo, organizada para diferentes clientes que depois se mantiveram fiéis à agência.

Gnyawali e Madhavan (2001, apud VASCONCELOS, 2004), ressaltam que alguns relacionamentos do empreendedor podem oferecer, ao novo negócio, recursos intangíveis, como legitimidade e status. Na empresa Laram, esse recurso destacou-se também na fase de desenvolvimento quando a empresa recebeu uma classificação de destaque junto à operadora CVC, o que fez aumentar a reputação da empresa perante os clientes da cidade e região.

Observou-se também que os relacionamentos estabelecidos evoluíram e foram se aprofundando à medida que os empreendedores puderam provar sua confiabilidade. Para 
Aldrich e Dubini (1991), a confiança é o elemento básico que determina a solidez das ligações da rede e da permanência do laço, reduzindo os riscos das partes envolvidas. Quando acessa um contato da sua rede, o empreendedor realiza uma troca e desta forma, faz uso de seu capital social, provocando um débito, para o qual há uma reciprocidade esperada.

A análise do caso sugere que ao manter uma rede de relacionamentos, do tipo formal ou informal, os empreendedores da Laram Turismo puderam acessar diferentes recursos e informações e, ainda, puderam aprender com os outros, uma vez que passaram a ter acesso a outras maneiras de se fazer as coisas.

Assim, partindo da idéia de que capital social é o benefício que pode ser derivado da rede social, pode-se afirmar que os diferentes recursos acessados pelos empreendedores do estudo contribuíram para a formação do seu capital social.

\section{Referências}

ADLER, P.S.; KWON, S. W. 2002. Social capital: prospects for a new concept. Academy of Management Review, v. 2, n. 1.

ALDRICH, H. R; DUBINI, P. 1991. Personal and Extend Networks Are Central to the Entrepreneurial Process. Journal of Business Venturing, v.6, p. 305-313.

; ELAM, A. B. 1997. A guide to surfing the social networks, In: Sue Birley and Dan Myzuka, editors, Managing Enterprise. London: Pitman. p. 143-148.

; REESE, P.R.; DUBINI, P. 1989. Woman on the verge of breakthrough: networking among entrepreneurs in the United States and Italy. Entrepreneurship and Regional Development, p. 339-355.

; ROSEN, B.; WOODWARD, W. 1987. The impact of social Networks on business foundings and profit: A longitudinal study. In J. Churchil (Ed.), Frontiers of Entrepreneurship Research. Babson College, p. 154-168.

; ZIMMER, C.1986. Entrepreneurship through social networks. In D. L. Sexton \& R. W. Smilor (Eds.), The Art and Science of Entrepreneurship, p. 3-23. Cambridge: Ballinger.

BARNIR, A.; SMITH, K. A. 2002. Interfirm alliances in the small business: The role of social networks. Journal of Small Business Management, v. 40, n.3, p. 219-232.

BIRLEY, S. 1985. The role of networks in the entrepreneurial process. Journal of Business Venturing, v.1., n.1, p. 107-117.

; CROMIE, S. 1988. Social networks and entrepreneurial in Northern Ireland. IN: Action Conference. Belfast, Ireland

; __ _ MYERS A. 1990. Entrepreneurial Networks: Their Emergence in Ireland and Overseas. International Small Business Journal, v. 9, n. 4, p. 56-74.

BÖGENHOLD, D. 2002. Social Capital as Strategic Element of Venture Creation. Annual Conference of the European Academy of Management Stockholm, 2, Annals.. 
BOURDIEU, P. 1986. The forms of capital. IN: J. G. Richardson (Ed.), Handbook of theory and research for the sociology of education. p. 241-258. Westport: Greenwood Press.

BORGES, C. V. 2005. Relacionamentos e competitividade. Revista HSM Management, n. 20, maio/ 2005. Disponível em: <http://www.hsm.com.br/canais/newsletters/hmu/hmu20.php>. Acesso em: 06/02/2008.

2007. Formation du capital social entrepreneurial. 168 f. Tese (Doutorado em Administração). Universidade de Montreal, Canadá.

BURT, R.S. 1992. Structural Holes: The Social Structure of Competition, Boston: Harvard Press.

COHOON, M.J.; ASPRAY, W. 2007. Networking and Access to Social Capital:. A Review of Research Literature on Women's Entrepreneurship in the Information Technology Field. Entrepreneurial report series. National Center for Women \& Information Technology. Disponível em: $<$ http://ncwit.org/pdf/4_networks_final.pdf > . Acesso em: 06/02/2008.

COLEMAN, J. S. 1988. Social capital in the creation of human capital. The American Journal of Sociology, v. 94, S95-S121.

GRANOVETTER, M.S. 1973. The Strength of Weak Ties. American Journal of Sociology, v. 78, n. 6, p. $1360-1380$.

1985. Economic action and social structure: A theory of embeddedness. American Journal of Sociology, v. 91, n.3, p. 481- 510.

GREVE, A.; SALAFF, J.W. 2003. Social Networks and Entrepreneurship. Entrperneuship Theory \& Practice, v. 28, n. 1, p. 1-22.

IBARRA, H. 1993. Personal networks of women and minorities in management: A conceptual framework. Academy of Management. The Academy of Management Review, v. 18, n. 1; p. 56-58, Jan.

JOHANNISSON, B. 1986. Network Strategies: Management, Technology, and Change. International Small Business Journal, v. 5, n. 1, p. 19-30.

1998. Personal networks in emerging knowledge-based firms: spatial and functional patterns. Entrepreneurship and Regional Development, v. 10, n. 4, p.297-312, Oct/Dec.

. 2000. Networking and entrepreneurial growth. IN: SEXTON, D. e LANDSTRON, H. (Ed.) Handbook of Entrepreunership. London: Blackwell.

LI, Y. H. P. 2004. Entrepreneurial Networks: A comparison of western and chinese concept. IN: Conference 13th Nordic Conference on Small Business Research,. 13. Annals....NCSB, may.

LIN, N. 2001a. Building a network theory of social capital. IN: N. Lin, K. S. Cook \& R. S. Burt (Eds.), Social capital: theory and research, p. 3-29, New York: Aldine de Gruyter.

2001b. Social Capital. A theory of Social Structure and Action, Cambridge: Cambridge University Press, Mintzberg, Henry \& B. Ahlstrand.

NAHAPIET, J.; GHOSHAL, S. 1998. Social capital, intellectual capital, and the organizational advantage. Academy of Management Review, v. 23 n. 2, p. 242-266.

OSTGAARD, T. O.; BIRLEY, S. 1994. Personal networks and firm competitive strategy: a strategic or coincidental match? Journal of Business Venturing, v.. 9, n. 4, p. $281-305$.

v. 36, n. $1, \overline{\text { p. } 37-50 .}$

1996. New venture growth and personal networks. Journal of Business Research, 
PORTES, A. 1998. Social capital: Its origins and the application in modern sociology. Annual Review of Sociology, v. 24, p. 1-24.

PUTNAM, R. 1995. Bowling alone: America's declining social capital. Journal of Democracy. n. 6:1, jan.

$\overline{\text { Schuster. }}$

2000. Bowling Alone: The Collapse and Revival of American Community, New York: Simon

RECUERO, Raquel da Cunha. 2004. Teoria das Redes e Redes Sociais na Internet. In: XXVII INTERCOM, na PUC/RS em Porto Alegre. Set.

RIBEIRO, J. C.; SANTOS, F. J. 2003. Redes, Investimento Direto Estrangeiro e Desenvolvimento Regional. In: Encontro Nacional Associação Portuguesa para o Desenvolvimento Regional. 10, Junho, 2003, Évora, Portugal. Disponível em: < http://www.apdr.pt/boletins/2003/Boletim2-2003.pdf $>$. Acesso em: 30/01/2008.

TRIVINOS, Augusto N. S. 1987. Introdução à pesquisa em ciências sociais: a pesquisa qualitativa em educação. São Paulo: Atlas.

VASCONCELOS, G.M.R. Inserção Social e Recursos: Um Estudo de Caso comparativa de criação e de desenvolvimento de novos negócios. $141 \mathrm{f}$. Dissertação (Mestrado em Administração) - Pontifícia Universidade Católica de Minas Gerais, Belo Horizonte, MG, 2004. Disponível em: $<$ http://www.pucminas.br/biblioteca/>. Acesso em: 29/09/2008

YIN, Robert K. 2001. Estudo de caso: planejamento e métodos. Porto Alegre: Bookman.

Recebido em: 14/04/2009 (1 $1^{\text {a }}$ versão) 20/10/2009 ( $2^{\mathrm{a}}$ versão)

Aprovado em: 22/03/2010 